\title{
N-Terminal Propeptide of Type III Collagen in Tracheal Fluid and Serum in Preterm Infants at Risk for Bronchopulmonary Dysplasia
}

\author{
MARKKU HEIKINHEIMO, RITVA HALILA, EINO MARTTINEN, AND KARI RAIVIO \\ Children's Hospital [M.H., E.M., K.R.] and Department of Medical Genetics [R.H.], University of Helsinki, \\ Finland
}

\begin{abstract}
Bronchopulmonary dysplasia (BPD) is a common pulmonary complication in preterm infants that leads to fibrosis of the bronchoalveolar walls and often to severe clinical consequences. Type III collagen is deposited early in progressive fibrosis. Because the N-terminal propeptide of type III collagen (PIIINP), a by-product of type III collagen synthesis, reflects the degree of pulmonary fibrosis in adults, we hypothesized that PIIINP in tracheal aspirates and/or serum may be a useful early marker of developing BPD in neonates. We serially measured PIIINP in tracheal fluid and serum samples during the first weeks of life in $\mathbf{4 1}$ consecutive respirator-treated preterm infants (mean birth weight $1067 \mathrm{~g}$, mean gestational age $28.3 \mathrm{wk}$ ). Eight of the infants died and 22 infants fulfilled the criteria for BPD at age $28 \mathrm{~d}$. The mean level of PIIINP decreased with advancing postnatal age in tracheal fluid but not in serum. The mean tracheal fluid PIIINP during $d 1$ and 2 of life, respectively, was 175 and $200 \mathrm{ng} / \mathrm{mg}$ protein in infants who were still in a respirator at age $28 \mathrm{~d}(n=13)$, 122 and $97 \mathrm{ng} / \mathrm{mg}$ protein in those who were weaned earlier $(n=20)$, and 50 and $30 \mathrm{ng} / \mathrm{mg}$ protein in those who died before age $28 \mathrm{~d}(n=8)$. These differences are not statistically significant, and the variability of the values was large. The PIIINP concentrations in tracheal aspirates of infants subsequently developing BPD did not differ from those without BPD. Neither did the levels correlate with the degree of BPD or radiologically defined fibrosis. In contrast to the findings in tracheal fluid, the serum PIIINP levels in infants subsequently developing BPD were significantly higher $(p=0.01)$ than those in infants without $\mathrm{BPD}$, the respective mean ( $90 \%$ confidence intervals) concentrations being 788 (range 519-1057) and 256 (range 171-341) ng/mL. We conclude that serum PIIINP should be further evaluated as an early marker of BPD, whereas tracheal fluid levels are useless for this purpose. (Pediatr Res 31: 340-344, 1992)
\end{abstract}

\section{Abbreviations}

PIIINP, N-terminal propeptide of type III collagen BPD, bronchopulmonary dysplasia RDS, respiratory distress syndrome

BPD is a common complication of respirator treatment of pulmonary disease in the preterm infant. Its main risk factors

Received Jujy 30, 1991; accepted November 4, 1991

Correspondence: Markku Heikinheimo, M.D., Children's Hospital, University of Helsinki, Stenbäckinkatu 11, 00290 Helsinki, Finland.

Supported by grants from The Academy of Finland, The Emil Aaltonen Foundation, The Finnish Cultural Foundation, The Paulo Foundation, and The Sigrid Jusélius Foundation. are immaturity, high inspired oxygen level, and barotrauma due to positive pressure ventilation (1). The incidence of BPD is roughly inversely proportional to gestational age.

The pathology of BPD develops from the typical findings of acute hyaline membrane disease through thickening and fibrosis of the bronchoalveolar walls $(2,3)$. Inflammatory cells and their proteolytic enzymes seem to contribute to tissue damage (4). In other types of organ fibrosis, connective tissue deposition begins with the synthesis of type III collagen, which is replaced by type I collagen at the later stages of disease (5-7). Consistent with this progression is the finding that the serum PIIINP, a by-product of type III collagen biosynthesis, is a sensitive early marker of developing liver and pulmonary fibrosis in adults $(8,9)$.

From the point of view of modifying treatment and estimating prognosis, identification of high risk of BPD or incipient disease in an individual infant would be desirable. Risk factors or scoring do not function well for this purpose (10), and methods to predict BPD by cytologic studies of tracheal aspirates have been unsatisfactory (11). Our hypothesis was that the PIIINP would appear in tracheal secretions and possibly in serum at the time when interstitial fibrosis in the lung starts to develop. To test this hypothesis, we performed a prospective clinical study on respirator-treated preterm infants.

\section{MATERIALS AND METHODS}

Patients. The study included 41 consecutive preterm infants with a birth weight of less than $1750 \mathrm{~g}$ who were intubated at birth, developed RDS, and required treatment in a respirator. Their clinical characteristics are shown in Table 1. RDS was defined clinically and radiologically as described (12), and the diagnosis of BPD was based on radiographic findings, need of extra oxygen, and clinical symptoms at age $28 \mathrm{~d}$ (13). None of the infants received surfactant treatment. Three infants had proven bacterial sepsis, and 22 were suspected of sepsis on the basis of clinical and laboratory data. An open ductus arteriosus required indomethacin treatment or surgery in 26 infants. Eight infants died at age 5 to $16 \mathrm{~d}$ (mean $10 \mathrm{~d}$ ), seven of them with RDS, five of them with infection (septicemia, pneumonia, necrotizing enterocolititis, or tracheobrochitis), two of them with grade IV intraventricular hemorrhage, and one of them with pulmonary hemorrhage.

Data concerning respirator treatment and respiratory status were recorded and included respirator settings, blood gases, and clinical complications such as pneumothorax, pulmonary hemorrhage, and atelectasis. The pulmonary problems in the patients are shown in Table 2.

This study was carried out in the Children's Hospital, University of Helsinki, and it was approved by the ethical committee. Written consent was obtained from the parents of the infants.

Radiographic examinations. Anterioposterior supine chest 
Table 1. Clinical characteristics of 41 infants studied

\begin{tabular}{lcc}
\hline & Mean & Range \\
\hline Gestational age $(w \mathrm{k})$ & 28.3 & $24-34$ \\
Birth wt $(\mathrm{g})$ & 1067 & $490-1620$ \\
Apgar score at $1 \mathrm{~min}$ & 4.3 & $1-9$ \\
Apgar score at $5 \mathrm{~min}$ & 6.6 & $1-10$ \\
\hline
\end{tabular}

Table 2. Pulmonary problems in 41 respirator-treated infants

\begin{tabular}{lrcc}
\hline & Yes $(n)$ & No $(n)$ & Dead $(n)$ \\
\hline Respirator treatment & & & \\
$\quad$ At 24 b & 39 & 2 & 0 \\
At 7 d & 34 & 16 & 1 \\
At 28 d & 13 & 20 & 8 \\
Pneumothorax & 9 & 32 & \\
Pulmonary hemorrhage & 1 & 40 & \\
Roentgenologic BPD at 28 d* & 22 & 10 & 8 \\
Infants fulfilling criteria for BPD & 22 & 10 & 8 \\
Roentgenologic fibrosis within & 25 & 15 & \\
$\quad$ first 28 d* & & &
\end{tabular}

* Roentgenograms of one patient were not available for analysis; fibrosis seen as interstitial prominence.

roentgenograms were read and scored by a pediatric radiologist (E.M.) on d 3, 7, 10, and 14 and thereafter at 1 -wk intervals. The severity of RDS was scored on a scale from 0 to 5 as suggested by Edwards et al. (12). Radiographic changes related to BPD were scored from 0 to 10 on the basis of fibrosis, interstitial air trapping, cardiovascular changes, hyperexpansion of the thorax, and the general impression of the roentgenograms (13). If the technical quality of chest radiograph was suboptimal, another taken on the previous or following day was used.

Samples. A total of 267 tracheal aspirates (an average of seven samples from each patient, range two to 11) were collected into DeLee traps at the time of routine suctioning of intubation tubes daily during the first week of life and weekly thereafter for the duration of respirator treatment. The samples (volume in the order of $0.2-1.0 \mathrm{~mL}$ ) were mixed with protease inhibitor PMSF and NEM (phenylmethylsulfonyl fluoride and N-ethylmaleimide) to the final concentrations of $25 \mathrm{mM}$ EDTA, $1 \mathrm{mM}$ paraaminobenzoic acid, $1 \mathrm{mM}$ PMSF, and $10 \mathrm{mM}$ NEM and kept at $-20^{\circ} \mathrm{C}$ until analyzed. A total of 63 serum samples from a subset of 32 infants were collected weekly at the time of routine laboratory tests. In addition, cord blood samples from 69 infants between 24 and 42 gestational wk, chosen at random from routine screening for congenital hypothyroidism (14), were studied to evaluate the ontogenesis of serum PIIINP concentrations.

Biochemical methods. The PIIINP concentrations in tracheal and serum samples were measured with a specific RIA (Hoechst AG, Frankfurt Am Main, Germany) (8) with an intraassay coefficient of variation of $4.8 \%$. The PIIINP content was measured in each individual sample, and no pooled samples were used. To correct for variable dilution of the tracheal aspirates, the results are expressed on the basis of protein concentration (as ng of PIIINP/mg protein) measured by the commercial protein assay (Bio-Rad Laboratories, Richmond, CA).

Statistical methods. Because of the large variation in the tracheal samples, means and $90 \%$ confidence intervals are given and nonparametric statistics (the Mann-Whitney test) were used for comparing prognostic groups. Cord serum PIIINP was related to gestational age using regression analysis, and postnatal serum values were compared using the Mann-Whitney test.

\section{RESULTS}

PIIINP in tracheal aspirates. The mean levels of PIIINP in tracheal fluid declined during the first week of life and more profoundly after age $3 \mathrm{wk}$ (Fig. 1). The concentration of PIIINP in the aspirates was not related to the age of onset, clinical stage,

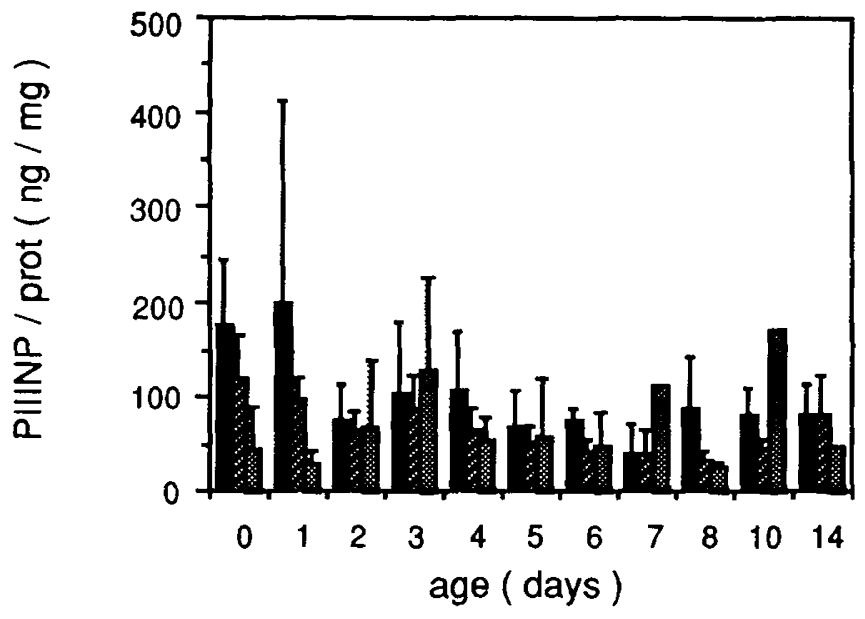

Fig. 1. Tracheal fluid PIIINP concentrations ( $\mathrm{ng} / \mathrm{mg}$ protein) (mean and the upper $90 \%$ confidence limit) during the first $2 \mathrm{wk}$ of life in various prognostic groups: infants who were still in a respirator at $\mathrm{d} 28$ (solid bars), infants who were weaned before d 28 (diagonally striped bars), and infants who died before d 28 (shaded bars).

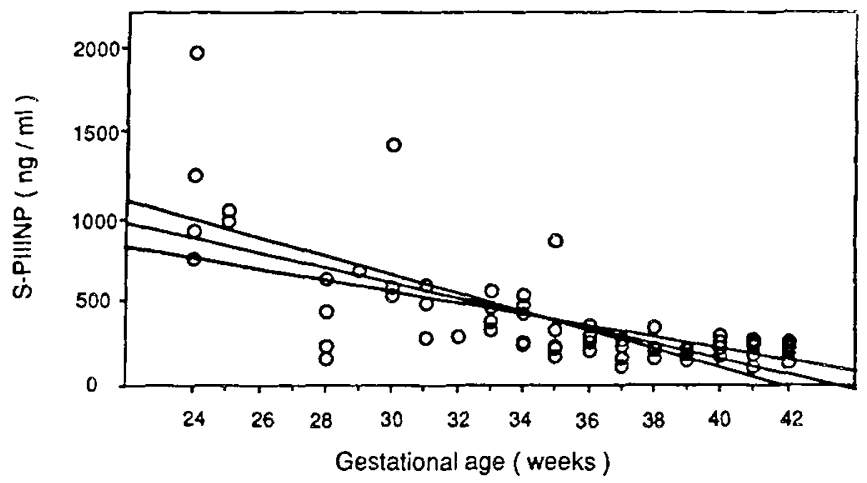

Fig. 2. PIIINP concentrations $(\mathrm{ng} / \mathrm{mL})$ in cord blood serum as a function of gestational age. The lines indicate $95 \%$ confidence limits.

or radiologic grade of RDS in the premature infants. Neither did the PIIINP concentration, measured at any time, correlate with the time of appearance of the first radiologic signs of BPD, the degree of radiologically defined fibrosis, or total BPD score. The mean $( \pm \mathrm{SD})$ radiologic BPD score at $28 \mathrm{~d}$ in infants with BPD was $6.6( \pm 2.2)$ (scale 1-10). The infants fulfilling the criteria for BPD did not differ from the other infants with respect to their PIIINP levels. The mean (90\% confidence limits) concentration of PIIINP at age 1 and $2 \mathrm{~d}$ was 175 (105-245) and $200(0-412)$ $\mathrm{ng} / \mathrm{mg}$ protein, respectively, in infants who were still in a respirator at age $28 \mathrm{~d}(n=13), 122(76-167)$ and $97(73-121) \mathrm{ng} / \mathrm{mg}$ protein in those who were weaned earlier $(n=20)$, and $50(7.8-$ $92)$ and $30(20-41) \mathrm{ng} / \mathrm{mg}$ protein in those who died before age $28 \mathrm{~d}(n=8)$, but the differences were not statistically significant (Fig. 1). The corresponding protein concentrations (90\% confidence intervals) in the aspirates from the three groups were 0.85 $(0.26-1.45), 0.81(0.30-1.32)$, and $2.21(0-7.3) \mathrm{mg} / \mathrm{mL}$ on $\mathrm{d} 1$ and $0.19(0.12-0.27), 0.33(0.18-0.48)$, and $0.42(0.31-0.81) \mathrm{mg} /$ $\mathrm{mL}$ on $\mathrm{d} 2$, respectively. Of these protein levels, the difference was statistically significant on 2 between the respirator group and the spontaneously breathing group $(p=0.0001)$ and between the respirator group and the group of infants who died before age $28 \mathrm{~d}(p=0.0001)$. Such differences in the PIIINP or protein content were not seen on $\mathrm{d} 3$ or later.

Other pulmonary problems or infections did not influence the PIIINP levels in tracheal fluid of these infants. No correlation with any respiratory parameter was detected.

PIIINP in serum. The PIIINP concentration in cord blood declined with advancing gestational age (Fig. $2, r=0.69, p=$ 
0.0001 ). However, in the postnatal samples, serum PIIINP levels showed no correlation with the postconceptional or postnatal age. Therefore, all samples of each prognostic group taken before age $28 \mathrm{~d}$ were analyzed together. The mean $(90 \%$ confidence interval) level during $\mathrm{d} 1$ through 22 (mean $5 \mathrm{~d}$ ) of life in infants subsequently developing BPD (32 samples) was 800 (498-1102) $\mathrm{ng} / \mathrm{mL}$, and in infants without BPD (22 samples) the mean level was $256(171-341) \mathrm{ng} / \mathrm{mL}$ ( $p=0.002$, Fig. 3 ). The mean $(90 \%$ confidence interval) concentrations were highest [794 (376$1213) \mathrm{ng} / \mathrm{mL}$ ] in infants who required respirator treatment beyond $\mathrm{d} 28$. Those infants who were weaned earlier had a mean level of $451(271-631) \mathrm{ng} / \mathrm{mL}$, and infants who died before $\mathrm{d} 28$ had a mean level of $284(149-418) \mathrm{ng} / \mathrm{mL}$ (Fig. 3). These differences were not statistically significant.

\section{DISCUSSION}

Various biochemical markers have been studied in infants with RDS and subsequent BPD. Tracheal fluid fibronectin has been reported to be elevated in premature infants with BPD as compared with infants with RDS or without respiratory difficulties (15). Proteolytic injury to the lung tissue in BPD is reflected in lower serum concentrations of $\alpha$-1-proteinase inhibitor, the major modulator of elastase activity. Elastase activity in tracheal aspirates, on the other hand, has been shown to be raised in infants with BPD (4). There is, however, no good biochemical or cytologic marker available for the early detection of preterm infants at risk for developing BPD. Our hypothesis was that PIIINP, reflecting the synthesis of type III collagen, would be such a marker. In adults, PIIINP levels have been found to be elevated in alveolar fluid in patients with idiopathic pulmonary fibrosis (16) and in serum and bronchoalveolar lavage fluid in patients with adult RDS (17) known to be complicated with severe fibrosis. In infants with advanced chronic lung disease, the ratio of type I/III collagen has been reported to be elevated, mainly because of elevated amounts of type I collagen in the lungs (18). The levels of type I or III collagen in ventilated infants have not, however, been studied during the development of lung damage. The PIIINP serum levels have also been shown to be an early indicator of liver fibrosis in patients with alcoholic liver disease and chronic active hepatitis $(8,19)$.

Contrary to our expectations, the PIIINP concentrations in $1 \mathrm{st}-\mathrm{wk}$ tracheal aspirates of infants developing BPD did not differ

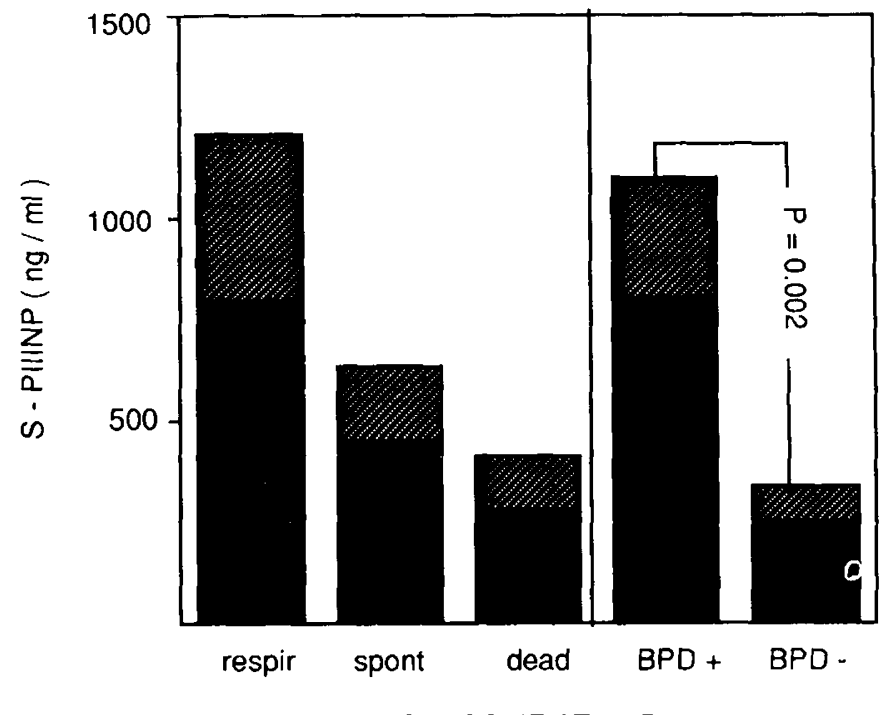

OUTCOME AT $28 \mathrm{D}$

Fig. 3. Serum PIIINP concentrations (ng/mL) (mean and the upper $90 \%$ confidence limit) in different prognostic groups according to the length of respirator treatment (respir, at respirator at age $28 \mathrm{~d}$; spont, spontaneously breathing at age $28 \mathrm{~d}$; dead, dead before age $28 \mathrm{~d}$ ) and in infants with BPD $(B P D+)$ and without BPD $(B P D-)$. from those without BPD. Neither did they correlate with the degree of BPD nor of radiologically defined fibrosis. Although infants with a long respirator treatment seemed to have higher tracheal aspirate PIIINP levels than those who were weaned earlier, the difference was not significant. This may be due to the large variation in volume, protein, and PIIINP concentration in tracheal samples, which is partly explained by the variable production of bronchoalveolar secretion and its variable dilution with saline used for flushing.

The tracheal fluid PIIINP levels were lowest in infants who died because of respiratory failure. This could be partly due to the fact that the most severe RDS is known to be associated with the most extensive protein leak to the alveolar fluid (20). This was also the case in our study: those infants who died early had the highest protein content in the aspirates, which partly accounts for the low PIIINP value per mg protein in this group of patients. Protein concentration is thus not an optimal reference basis for expressing the results. Tracheal fluid albumin and urea were not studied in our work, but these could possibly serve as alternative references bases to express the PIIINP results. The difference in tracheal fluid PIIINP concentration was not evident on $\mathrm{d} 3$ or later, when there were no more differences in the protein concentrations of the tracheal aspirates. On the other hand, the lowest serum PIIINP concentrations were also noted in those infants with the worst prognosis, suggesting that factors other than the protein content may contribute to the differences in tracheal aspirates as well.

The serum PIIINP concentration in healthy children is high at birth and declines during childhood before it again increases at puberty $(21,22)$. The fetal serum levels or the effect of gestational age on serum PIINP concentrations have not been studied previously. The analysis of cord blood sera showed a clear decline in PIIINP concentrations with advancing gestation. However, the serum levels in preterm infants were not correlated with postnatal or postconceptional age, suggesting that factors other than maturity have a dominant influence. The differences between the prognostic groups suggest that lung damage may be such a factor.

Our finding of somewhat higher serum levels of PIIINP in infants subsequently developing $\mathrm{BPD}$, as compared with infants without BPD, encourages further studies on the possible use of this marker for monitoring preterm infants at risk for BPD. Tracheal samples appear useless for this purpose.

\section{REFERENCES}

1. O'Brodovich HM, Mellins RB 1985 Bronchopulmonary dysplasia. Unresolved neonatal acute lung injury. Am Rev Respir Dis 132:694-709

2. Taghizadeh A, Reynolds EOR 1976 Pathogenesis of bronchopulmonary dysplasia. Arch Pathol Lab Med 107:603-608

3. Bonikos DS, Bensch KG, Northway Jr WH, Edwards DK 1976 Bronchopulmonary dysplasia: the pulmonary pathologic sequel of necrotizing bronchiolitis and pulmonary fibrosis. Hum Pathol 7:643-666

4. Merritt TA, Cochrane CG, Holcomb K, Bohl B, Hallman M, Strayer D, Edwards DK 1983 Elastase and alfa-1-proteinase inhibitor activity in tracheal aspirates during respiratory distress syndrome: role of inflammation in the pathogenesis of bronchopulmonary dysplasia. J Clin Invest 72:656-666

5. Madri JA, Furthmayr H 1980 Collagen polymorphism in human lung: an immunohistochemical study of pulmonary fibrosis. Hum Pathol 11:353365

6. Bateman E, Turner-Warwick M, Adelman-Grill BC 1981 Immunohistochemical study of collagen types in human foetal lung and fibrotic lung disease. Thorax 36:645-653

7. Rennard SJ, Crystal RG 1982 Lung. In: Weiss JB, Jayson JV (eds) Collagen in Health and Disease. Churchill Livingstone, Edinburgh, UK, pp 376-387

8. Rohde H, Vargas L, Hahn E, Kalbfleisch H, Bruguera M, Timpl R 1979 Radioimmunoassay for type III procollagen peptide and its application to human liver disease. Eur J Clin Invest 9:451-459

9. Low RB, Cutroneo KR, Davis GS, Giancola MS 1983 Lavage of type III procollagen $\mathrm{N}$-terminal peptides in human pulmonary fibrosis and sarcoidosis. Lab Invest 48:755-759

10. Kraybill EN, Runyan DK, Bose CL, Khan JH 1989 Risk factors for chronic lung disease in infants with birth weights of 751 to 1000 grams. J Pediatr 115:115-120

11. Merritt TA, Stuard ID, Puccia J, Wood B, Edwards DK, Finkelstein J, Shapiro DL 1981 Newborn tracheal aspirate cytology: classification during respira- 
tory distress syndrome and bronchopulmonary dysplasia. J Pediatr 98:949956

12. Edwards DK, Hilton SVW, Merritt TA, Hallman M, Mannino F, Boynton BR 1985 Respiratory distress syndrome treated with human surfactant: radiographic findings. Radiology 157:329-334

13. Toce SS, Farrel PM, Leavitt LA, Samuels DP, Edwards DK 1984 Clinical and roentgenographic scoring systems for assessing bronchopulmonary dysplasia. Am J Dis Child 138:581-585

14. Virtanen M, Perheentupa J, Mäenpää J, Pitkänen L, Pikkarainen J 1984 Finnish national screening for hypothyroidism. Few false positives, early therapy. Eur J Pediatr 143:2-5

15. Gerdes JS, Yoder MC, Douglas SD, Paul M, Harris MC, Polin RA 1986 Tracheal lavage and plasma fibronectin: relationship to respiratory distress syndrome and development of bronchopulmonary dysplasia. J Pediatr 108:601-606

16. Cantin AM, Boileau R, Bégin R 1988 Increased procollagen III aminoterminal peptide-related antigens and fibroblast growth signals in the lungs of patients with idiopathic pulmonary fibrosis. Am Rev Respir Dis 137:572-578

17. Entzian P, Hückstädt A, Kreipe H, Barth J 1990 Determination of serum concentrations of type III procollagen peptide in mechanically ventilated patients. Pronounced augmented concentrations in the adult respiratory distress syndrome. Am Rev Respir Dis 142:1079-1082

18. Shoemaker CT, Reiser KM, Goetzman BW, Last JA 1984 Elevated ratios of type I/III collagen in the lungs of chronically ventilated neonates with respiratory distress. Pediatr Res 18:1176-1180

19. Niemelä O, Risteli L, Sotaniemi EA, Risteli J 1983 Aminoterminal propeptide of type III procollagen in serum in alcoholic liver disease. Gastroenterology $85: 254-259$

20. Jobe A, Ikemagi M, Jacobs H, Jones S, Conaway D 1983 Permeability of premature lamb lungs to protein and the effect of surfactant on the permeability. J Appl Physiol 55:169-176

21. Trivedi P, Cheeseman P, Portmann B, Hegarty J, Mowat AP 1985 Variation in serum type IIl procollagen peptide with age in healthy subjects and its comparative value in the assessment of disease activity in children and adults with chronic active hepatitis. Eur J Clin Invest 15:69-74

22. Danne T, Grüters A, Schuppan D, Quantas N, Enders I, Weber B 1989 Relationship of procollagen type III propeptide-related antigens in serum to somatic growth in healthy children and patients with growth disorders. J Pediatr 114:257-260 